\title{
Motor neuron cell-nonautonomous rescue of spinal muscular atrophy phenotypes in mild and severe transgenic mouse models
}

\author{
Yimin Hua, ${ }^{1,2}$ Ying Hsiu Liu, ${ }^{2}$ Kentaro Sahashi, ${ }^{2}$ Frank Rigo, ${ }^{3}$ C. Frank Bennett, ${ }^{3}$ \\ and Adrian R. Krainer ${ }^{2}$ \\ ${ }^{1}$ Jiangsu Key Laboratory of Translational Research and Therapy for Neuro-Psycho-Diseases and Institute of Neuroscience, \\ Soochow University, Suzhou, Jiangsu 215021, China; ${ }^{2}$ Cold Spring Harbor Laboratory, Cold Spring Harbor, New York 11724 , \\ USA; ${ }^{3}$ Isis Pharmaceuticals, Carlsbad, California 92010, USA
}

\begin{abstract}
Survival of motor neuron (SMN) deficiency causes spinal muscular atrophy (SMA), but the pathogenesis mechanisms remain elusive. Restoring SMN in motor neurons only partially rescues SMA in mouse models, although it is thought to be therapeutically essential. Here, we address the relative importance of SMN restoration in the central nervous system (CNS) versus peripheral tissues in mouse models using a therapeutic spliceswitching antisense oligonucleotide to restore SMN and a complementary decoy oligonucleotide to neutralize its effects in the CNS. Increasing SMN exclusively in peripheral tissues completely rescued necrosis in mild SMA mice and robustly extended survival in severe SMA mice, with significant improvements in vulnerable tissues and motor function. Our data demonstrate a critical role of peripheral pathology in the mortality of SMA mice and indicate that peripheral SMN restoration compensates for its deficiency in the CNS and preserves motor neurons. Thus, SMA is not a cell-autonomous defect of motor neurons in SMA mice.
\end{abstract}

[Keywords: spinal muscular atrophy; SMN2; SMN; antisense oligonucleotide; mouse models]

Supplemental material is available for this article.

Received November 30, 2014; revised version accepted December 22, 2014.

Spinal muscular atrophy (SMA) is the leading genetic cause of pediatric mortality and is characterized by weakness and paralysis of voluntary muscles due to spinal cord $\alpha$-motor neuron degeneration (Crawford and Pardo 1996). Homozygous loss or mutation of the survival motor neuron 1 (SMN1) gene is responsible for SMA (Lefebvre et al. 1995). Humans have a closely related paralog, SMN2; both genes are ubiquitously expressed and encode an identical full-length protein. However, a nucleotide transition (C6T) in SMN2 exon 7 causes predominant skipping of the exon during pre-mRNA splicing, resulting in a truncated protein isoform (SMN $\Delta 7$ ) as the major product, which is rapidly degraded (Lorson et al. 1999; Monani et al. 1999). SMN2 still expresses some full-length SMN mRNA and protein, which is not sufficient to compensate for the lack of SMN1 but is essential for the survival of SMA patients. SMN2 is an SMA modifier: Patients or mouse models carrying one or two copies of SMN2 generally have the most severe form of SMA (type I), whereas those with

Corresponding authors: krainer@cshl.edu, huay@cshl.edu,ymhua@suda. edu.cn

Article published online ahead of print. Article and publication date are online at http://www.genesdev.org/cgi/doi/10.1101/gad.256644.114. a higher copy number have milder phenotypes (type II, III, or IV) (McAndrew et al. 1997).

SMN forms a complex with Gemin proteins and acts as a chaperone to assist the assembly of U snRNPs, essential components of the spliceosome (Meister et al. 2001). SMN is also thought to be involved in axonal mRNP transport in motor neurons (Rossoll et al. 2003). However, how suboptimal levels of SMN lead to SMA is largely unknown. Multiple studies in SMA mouse models revealed widespread synaptic defects in neuromuscular junctions (NMJs), including neurofilament accumulation, poor terminal arborization, immature endplates, reduced quantal content, disturbed calcium homeostasis, and decreased remodeling potential; these defects precede motor neuron death (Cifuentes-Diaz et al. 2002; Le et al. 2005; Jablonka et al. 2007; Kariya et al. 2008; Murray et al. 2008, 2012; Kong et al. 2009; Ling et al. 2010; Ruiz et al. 2010; Lee et al. 2011), suggesting that the NMJ alterations are the initial consequence of SMN deficiency,

(C) 2015 Hua et al. This article is distributed exclusively by Cold Spring Harbor Laboratory Press for the first six months after the full-issue publication date (see http://genesdev.cshlp.org/site/misc/terms.xhtml). After six months, it is available under a Creative Commons License (Attribution-NonCommercial 4.0 International), as described at http:// creativecommons.org/licenses/by-nc/4.0/. 
which then results in motor neuron death and muscle atrophy.

Recently, Ling et al. (2012) systematically examined NMJs in a severe mouse model (SMN $\Delta 7$ ) and found that several muscles are selectively denervated to varying degrees due to failure in synapse maintenance rather than initial synapse formation. Sensory motor synaptic defects in the spinal cord have also been observed (Ling et al. 2010; Park et al. 2010; Mentis et al. 2011). Three recent studies demonstrated that both peripheral and central synaptic defects are autonomously caused by insufficient levels of SMN in motor neurons (Gogliotti et al. 2012; Lee et al. 2012; Martinez et al. 2012). However, increasing SMN levels in motor neurons, although sufficient to restore both NMJ and sensory motor synaptic integrity, only partially ameliorates the phenotype of SMA mice, including a limited increase in survival (Gogliotti et al. 2012; Lee et al. 2012; Martinez et al. 2012). These data suggest that defects in tissues other than motor neurons contribute substantially to the rapid mortality of mice with severe SMA.

SMA patients and mouse models exhibit widespread abnormalities in various cell types, tissues, and organs, aside from spinal cord motor neurons (Hamilton and Gillingwater 2013). In the central nervous system (CNS), impaired neuritogenesis and neurogenesis in the hippocampus and retina have been observed (Wishart et al. 2010; Liu et al. 2011). In the peripheral nervous system (PNS), loss of Schwann cells and sensory neuropathy have been documented (Rudnik-Schoneborn et al. 2003; Murray et al. 2012; Yonekawa et al. 2013). Muscle atrophy is one of the two hallmarks of SMA. However, although there is a reduction in muscle fiber number and size (due to compromised muscle growth, lack of myofiber maturation, and premature differentiation of satellite cells), the importance of muscle SMN levels in SMA pathology is controversial (Braun et al. 1995; Gavrilina et al. 2008; Lee et al. 2011; Hayhurst et al. 2012). Martinez et al. (2012) recently demonstrated that increased SMN in muscle-including myoblasts and satellite cells, two cell types critical for muscle growth and maintenanceslightly extends the survival of SMA mice, supporting the conclusion that the deficiency of SMN in muscles also contributes to the mortality of SMA mice.

Distal necrosis is a phenotypic feature in both mild and severe SMA mouse models (Hsieh-Li et al. 2000; Tsai et al. 2006; Narver et al. 2008); digital necrosis has also been observed, albeit infrequently, in infants with severe SMA (Araujo et al. 2009; Rudnik-Schoneborn et al. 2010). Furthermore, cardiac failure is a common phenotypic trait in severe mouse models and has also been reported in some severe SMA patients (Rudnik-Schoneborn et al. 2008; Bevan et al. 2010; Heier et al. 2010; Shababi et al. 2010). In addition, bone defects were reported in both SMA patients and mouse models (Shanmugarajan et al. 2007, 2009). More recently, Bowerman et al. (2012) uncovered abnormal expansion of $\alpha$ cells and shrinkage of $\beta$ cells in the pancreatic islets of SMA mice, resulting in hyperglucagonemia and defective glucose metabolism. In spite of these global peripheral defects seen in both patients and animal models, their importance in SMA pathogenesis has been largely overlooked.

2'-O-(2-methoxyethyl) (MOE)-modified antisense oligonucleotides (ASOs) with a phosphorothioate backbone that target an hnRNP-A1/A2-dependent splicing silencer, ISS-N1, in SMN2 intron 7 restore full-length SMN expression by correcting SMN2 exon 7 splicing (Singh et al. 2006; Hua et al. 2007, 2008, 2010). We recently showed that an 18mer ASO (ASO10-27, also known as ISIS$\mathrm{SMN}_{\mathrm{Rx}}$ ) robustly rescues severe SMA mice when delivered systemically, whereas much more modest, albeit significant, rescue is obtained by intracerebroventricular (ICV) administration to selectively increase SMN levels in the CNS (Hua et al. 2011). These data clearly demonstrated that SMN expression in peripheral tissues plays an important role in murine SMA pathology. The ASO does not cross an intact adult blood-brain barrier (BBB). However, the BBB of neonatal mice allows some ASO molecules to penetrate into the CNS after systemic administration, resulting in moderate increases in SMN2 exon 7 inclusion in both the brain and spinal cord (Hua et al. 2011). This raised the questions of whether BBB permeability is essential for the long-term rescue achieved by systemic ASO delivery in neonatal mice and therefore whether increasing SMN in the CNS is necessary-although not sufficient-for efficient rescue of the SMA phenotype. Answering these questions is of paramount importance for understanding SMA pathogenesis in the mouse models and has clinical implications as well. Currently, ASO10-27 is in phase 3 clinical trials and is being delivered intrathecally to SMA infants and children. Whether it will be desirable to deliver this and other SMA drugs also by systemic routes needs to be addressed. Answering this important question will help to optimize treatment modalities.

Here, we address these questions using both mild and severe SMA mouse models. We took advantage of ASO10-27 and a complementary decoy oligonucleotide designed to neutralize ASO10-27 (Rigo et al. 2014). We combined subcutaneous (SC) treatment of ASO10-27 and ICV treatment with excess decoy in both the mild and severe models; the decoy efficiently abrogated the effect of ASO10-27 in the CNS. To our surprise, increasing SMN levels in the CNS was not required in either mouse model for efficient phenotypic rescue. In the severe model, increasing SMN levels in peripheral tissues exclusively was sufficient for the rescue of motor neurons and long-term survival, indicating that peripheral defects play a key role in SMA pathogenesis.

\section{Results}

Peripheral SMN restoration completely rescued distal necrosis in a mild SMA mouse model

Multiple SMA mouse models have been reported. One mild model $\left(\mathrm{Smn}^{-1-} ; \mathrm{SMN2} 2^{2 \mathrm{TG} / 2 \mathrm{TG}}\right)$ carries four copies of an SMN2 transgene in a $\mathrm{FVB} / \mathrm{N}$ strain background; it survives normally, but several days after birth, it develops edema in its tail, which appears short and thick (Hsieh-Li 
et al. 2000). At $\sim 3 \mathrm{wk}$ postnatally, necrosis develops at the tail tip, gradually spreading to the entire tail until it is completely lost. Necrosis and subsequent loss of the ear pinnae also occur after $\sim 1$ mo postnatally. We previously showed that the onset of distal necrosis in this mouse model can be delayed to 1-2 mo by embryonic or neonatal ICV injection of ASO10-27 (Hua et al. 2010). Here, we asked whether the necrotic phenotype in this model can be rescued by systemic ASO treatment.

Newborn pups were administered two SC injections of ASO10-27 at 40, 80, or $120 \mathrm{mg} / \mathrm{kg}$; one injection was on postnatal day 0 (P0), and the other was on P2. All doses tested completely prevented necrosis in both the tail and ear pinnae of the treated mice throughout their lives. However, the tails of mice treated with the highest dose were significantly longer compared with the lower doses, although still $\sim 1.6 \mathrm{~cm}$ shorter than those of untreated heterozygous mice (Fig. 1A,B). We further tested whether delayed treatment could also achieve a similar rescue. Mice were treated with two SC injections of $120 \mathrm{mg} / \mathrm{kg}$ ASO10-27 at 1 or 2 wk of age. Again, distal necrosis was completely prevented, and the tail length for all mice was $>5 \mathrm{~cm}$ long (Fig. 1C). Since edema in the tail appears in the first postnatal week and tail necrosis starts early during the fourth week, these data demonstrate that SC ASO treatment at a relatively late stage can still reverse the pathological process and robustly restore the normal growth and maintenance of the tail.

As mentioned above, subcutaneously injected ASO can cross the immature BBB of neonatal mice and moderately increase SMN levels in the CNS (Hua et al. 2011). To address whether the increase in SMN in the CNS is required for rescue of distal tissue necrosis, we treated mice after the onset of necrosis, between P22 and P26 (Fig. 1C,D). At this postnatal stage, SC delivery of ASO10-27 had no effect on SMN2 splicing in the brain and spinal cord based on analysis by radioactive RT-PCR, indicating that the BBB is already fully established and impermeable to the ASO (Fig. 1E,F). Interestingly, the delayed treatment still rescued the healthy portion of the tail and prevented ear necrosis (Fig. 1D). These data demonstrate that increasing the SMN levels in peripheral tissues is sufficient to rescue the phenotype of mild SMA mice and also that therapy to prevent necrosis has a broad temporal window.

\section{Coadministration of decoy with ASO10-27 had no negative effect on tail growth and maintenance in mild SMA mice}

We used a novel "decoy" approach to further evaluate the therapeutic importance of the SMN increase in the CNS of the mild SMA mouse model. The decoy is a synthetic oligonucleotide harboring the same modifications as the therapeutic ASO10-27, also $18 \mathrm{nt}$ long, and is exactly complementary to ASO10-27 in sequence; thus, it is a "sense" oligonucleotide that can neutralize the effect of ASO10-27 by sequestering it through Watson-Crick basepairing (Rigo et al. 2014). To determine the ICV dose of decoy required to effectively sequester the systemically
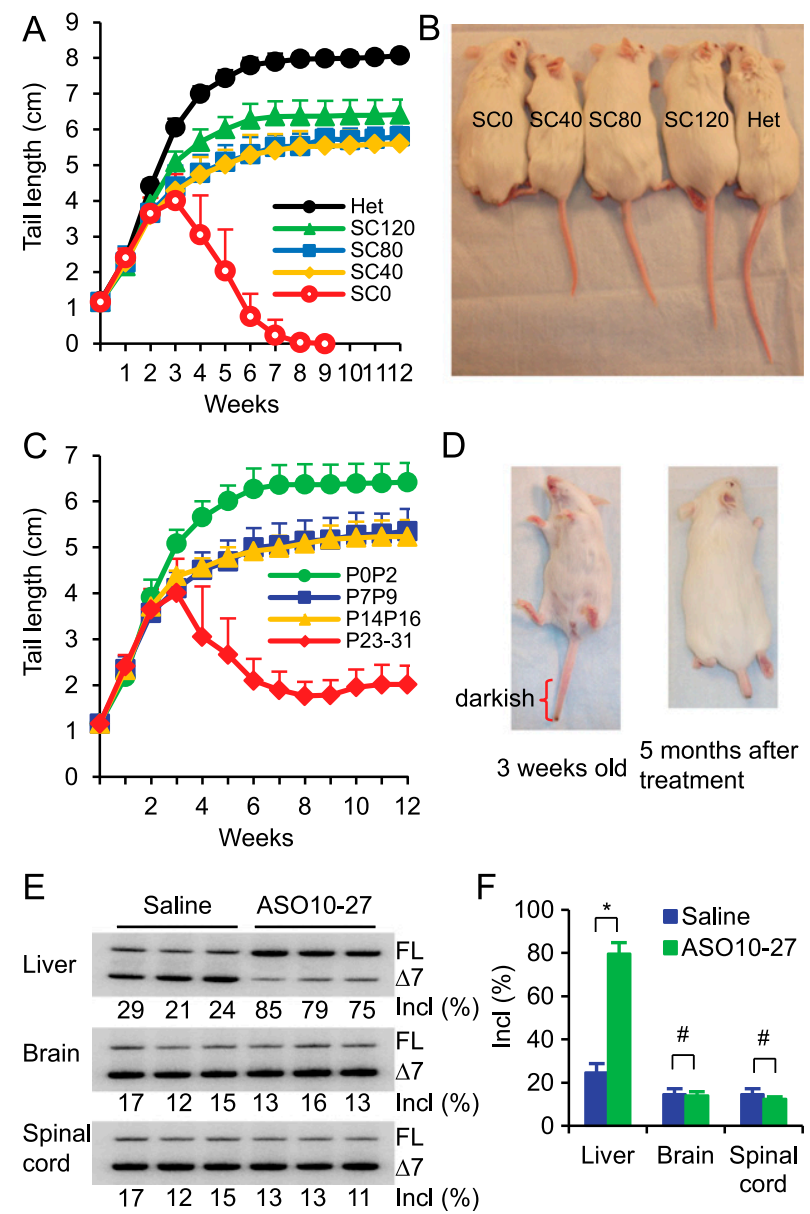

Figure 1. Systemic delivery of ASO10-27 promotes tail growth and prevents necrosis in mild SMA mice. $(A)$ Dose-dependent tail growth and complete prevention of tail necrosis were achieved by two SC injections of ASO10-27 at $0 \mathrm{mg} / \mathrm{kg}$ (SCO, $n=13), 40 \mathrm{mg} / \mathrm{kg}(\mathrm{SC} 40, n=13), 80 \mathrm{mg} / \mathrm{kg}$ (SC80, $n=14)$, or 120 $\mathrm{mg} / \mathrm{kg}(\mathrm{SC} 120, n=18)$ on $\mathrm{P} 0$ and $\mathrm{P} 2$, one injection per day. Untreated heterozygous mice (Het, $n=13$ ) were used as normal controls. Tail length was measured weekly for up to 3 mo. (B) Pictures of 3-mo-old mice treated as in $A$. (C) Prevention of tail necrosis was achieved by two late SC injections at $120 \mathrm{mg} / \mathrm{kg}$. Injections were performed on $\mathrm{P} 0$ and $\mathrm{P} 2(\mathrm{POP} 2, n=13)$, on $\mathrm{P} 7$ and P9 (P7P9, $n=20)$, on P14 and P16 (P14P16, $n=12)$, or between $\mathrm{P} 23$ and P31 (P23-31, $n=11)$ for each mouse. For the P23-P31 group, necrosis was just starting on the tail tip. $(D)$ Mice in the P23-P31 group at the time of the first injection of ASO10-27 (left) and 5 mo after treatment (right). (E) Analysis of SMN2 exon 7 inclusion in the liver, brain, and spinal cord of P23-P31 mice by radioactive RT-PCR. Saline treatment was used as a control. Tissues were collected $5 \mathrm{~d}$ after the second injection. (FL) Fulllength transcript; ( $\Delta 7)$ exon 7-skipped transcript; [Incl (\%)] $100 \times$ $\mathrm{FL} /(\mathrm{FL}+\Delta 7)$. $(F)$ Histogram of exon 7 inclusion data from $E(n=$ 3). ( $^{\star} P<0.001 ;(\#) P>0.05$.

administered therapeutic ASO that reaches the CNS, we tested two doses, 10 and $20 \mu \mathrm{g}$, based on our past experience with ASO10-27 administered by ICV and SC routes (Hua et al. 2010, 2011).

We injected the decoy solution ICV at P0-P1; at P0-P2, we also gave two SC injections of ASO10-27 at $120 \mathrm{mg} / \mathrm{kg}$ 
per injection. SMN2 exon 7 inclusion levels in the spinal cord, brain, and liver, analyzed on P7, indicate that $10 \mu \mathrm{g}$ of decoy was sufficient to block splicing correction by sequestering the ASO10-27 molecules that penetrated the CNS after the double SC dosing (Fig. 2A,B). The decoy by itself had no toxicity and did not affect SMN2 splicing (Supplemental Fig. S1). Interestingly, coadministration of ASO10-27 and the decoy had no effect on tail growth compared with ASO10-27 treatment alone, and no necrosis occurred in any mouse treated with both ASO10-27 and the decoy (Fig. 2C). These data confirm that the distal necrosis observed in mild SMA mice is mainly or exclusively a peripheral defect.

\section{Coadministration of decoy did not reduce survival of a severe SMA mouse model}

We next used the same decoy approach to address whether increasing SMN in the CNS is essential to rescue severe SMA mice. The phenotype of the severe SMA model $\left(S \mathrm{Sn}^{-/-} ; S M N 2^{2 \mathrm{TG} / 0}\right)$, generated by crossbreeding the mild SMA mice $\left(\mathrm{Smn}^{-/-} ; S M N 2^{2 \mathrm{TG} / 2 \mathrm{TG}}\right)$ with heterozygous knockout mice $\left(\mathrm{Smn}^{+/-}\right)$, is similar to that of the SMN $\Delta 7$ model, including characteristic NMJ defects, motor neuron loss, and a life span of 1-wk (Riessland et al. 2010). We set up three experimental groups: Mice in the untreated group did not receive either ASO10-27 or the decoy but
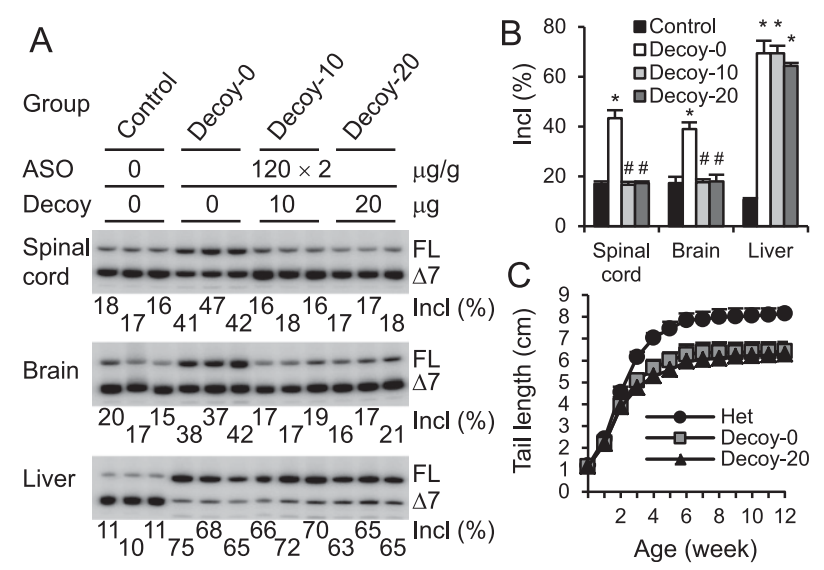

Figure 2. Intracerebroventricularly injected decoy oligonucleotide neutralized the CNS effect of subcutaneously injected ASO10-27 but had no negative impact on tail growth and prevention of necrosis in mild SMA mice. (A) RT-PCR analysis of SMN2 exon 7 splicing in the spinal cord, brain, and liver of mice that received two SC injections of ASO10-27 at $120 \mathrm{mg} / \mathrm{kg}$ per injection on $\mathrm{P} 0$ and $\mathrm{P} 2$, one injection per day, together with ICV delivery of $0 \mu \mathrm{g}$ of decoy (decoy-0) or $10 \mu \mathrm{g}$ of decoy (decoy$10)$ on P0 or $20 \mu \mathrm{g}$ of decoy (decoy-20) on P0 and P2 (10 $\mu \mathrm{g}$ per day). The control group was treated with saline for both SC and ICV injections (untreated). Tissues were collected on P7. (B) Histogram of exon 7 inclusion data from $\left.A(n=3) .{ }^{*}\right) P<0.001$ versus the untreated group; (\#) $P>0.05$ versus untreated mice. $(C)$ Tail growth of decoy-0 $(n=18)$ and decoy-20 $(n=15)$ groups as described in $A$. Tail length was measured weekly for up to $3 \mathrm{mo}$; no necrosis occurred in decoy-20 mice throughout their lives. Heterozygous littermates (Het, $n=13$ ) were used as normal controls. just saline, the SC-alone group was treated with one SC injection of ASO10-27 at $120 \mathrm{mg} / \mathrm{kg}$ per day from P0 to $\mathrm{P} 2$, and the $\mathrm{SC}+$ decoy group was treated as the SC-alone group, but with additional ICV administration of the decoy at a total dose of $30 \mu \mathrm{g}(10 \mu \mathrm{g}$ on P0 plus $20 \mu \mathrm{g}$ on P2). We collected the spinal cord, brain, and liver on P7; extracted total RNA; and analyzed it by radioactive RT-PCR.

SC administration of ASO10-27 alone promoted strong SMN2 exon 7 inclusion in the liver and moderate inclusion in the CNS; additional ICV delivery of the decoy strikingly decreased exon 7 inclusion in the CNS but did so only marginally in the liver (from $72 \%$ to $62 \%$ ) (Fig. $3 \mathrm{~A}, \mathrm{~B})$. In the SC+decoy group, the extent of SMN2 exon 7 inclusion in either the brain or spinal cord was slightly higher than that in the untreated group, which we attribute to exacerbation of the splicing defect at the end stage of the disease in the untreated group, as shown in our previous study (Sahashi et al. 2012). Consistent with this interpretation, there was no difference in exon 7 inclusion in the CNS between the SC+decoy and untreated groups in both mild SMA mice (Fig. 2A,B) and healthy heterozygous littermates (Supplemental Fig. S1).

Western blot analysis showed corresponding changes at the SMN protein level in the liver, brain, and spinal cord of mice between the SC+decoy and SC-alone groups (Fig. 3C,D). We also performed immunohistochemistry of brain and spinal cord sections with a polyclonal antibody that recognizes the phosphorothioate backbone in both ASO10-27 and the decoy and with a monoclonal antibody against SMN. Tissue samples were collected on P7. Whereas SC dosing alone resulted in increased SMN staining in the brain and spinal cord, the additional decoy treatment markedly reduced SMN staining in both tissues (Fig. 4; Supplemental Fig. S2). Furthermore, we performed immunofluorescence using antibodies against the motor neuron marker choline acetyltransferase (ChAT) and against SMN to count gems in spinal cord $\alpha$-motor neurons in the ventral horn of lumbar segments L1-L2. A striking reduction in the number as well as the size of SMN-positive gems was observed after the additional ICV decoy treatment compared with SC dosing of ASO10-27 alone (Fig. 5), again demonstrating the effectiveness of the decoy.

Mice treated with SC dosing alone had a median survival of $237 \mathrm{~d}$ (Fig. 6A); the $\sim 24$-fold median survival increase compared with untreated mice, which survived $\sim 10 \mathrm{~d}$, is consistent with our previous data (Hua et al. 2011). Surprisingly, in spite of its successful abrogation of the SMN increase in the CNS, the decoy treatment did not significantly decrease survival compared with SC dosing alone: The median survival in the SC+decoy group reached $212 \mathrm{~d}$ (Fig. 6A). Remarkably, the majority of the rescued mice in both groups showed no signs of motor defects: They could run, climb, and hang from their forelimbs. We recorded the body weight weekly for up to $2 \mathrm{mo}$; the additional decoy treatment had no impact on weight gain (Fig. 6B). In both groups, the tail length of the rescued mice ranged from 3 to $5 \mathrm{~cm}$, and most of them developed late tail necrosis at $\sim 1$ yr (data not shown). 
A

B
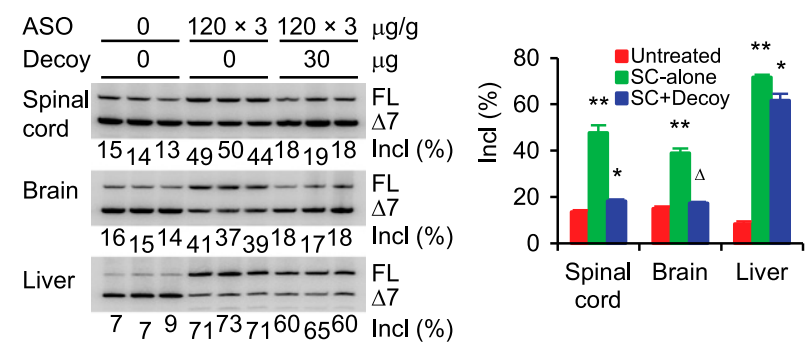

C ASO $\frac{0}{0} \frac{120 \times 3}{0} \frac{120 \times 3}{30} \mu \mathrm{g} / \mathrm{g}$

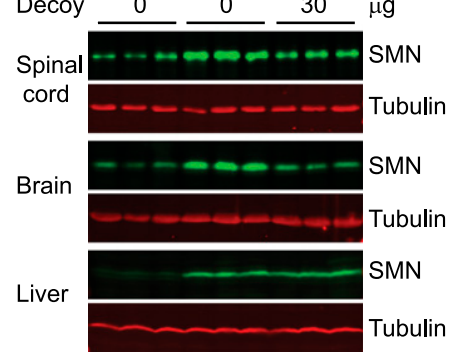

D

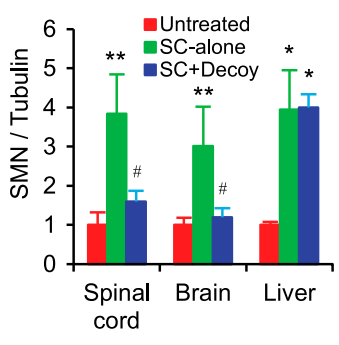

Figure 3. ICV delivery of decoy abrogated the CNS effect of subcutaneously administered ASO10-27 in severe SMA mice. (A) RT-PCR analysis of SMN2 exon 7 splicing in the spinal cord, brain, and liver of mice treated with three SC injections of ASO10-27 at $120 \mathrm{mg} / \mathrm{kg}$ per injection between P0 and P2, one injection per day, together with ICV injection of saline (SCalone) or $30 \mu \mathrm{g}$ of decoy (SC+decoy) on P0 $(10 \mu \mathrm{g})$ and P2 $(20 \mu \mathrm{g})$. The control group was treated with saline for both SC and ICV injections (untreated). Tissues were collected on P7. (B) Histogram of exon 7 inclusion data from $A(n=3) .\left(^{\star \star}\right) P<0.01$ versus the other two groups; $\left(^{\star}\right) P<0.01$ versus untreated mice; $(\Delta) P<$ 0.05 versus untreated mice. $(C)$ Western blotting analysis of SMN levels in the spinal cord, brain, and liver of mice as described in A. Tissues were collected on P7. Tubulin was used as a loading control. $(D)$ Histogram of SMN levels relative to tubulin levels from $C(n=3)$. Data were normalized to the untreated group. $\left({ }^{\star \star}\right) P<0.05$ versus the other two groups; $\left(^{\star}\right) P<$ 0.01 versus untreated mice; (\#) $P>0.05$ versus untreated mice.

Coadministration of the decoy with ASO10-27 did not negatively impact motor neuron count and NMJ integrity

Motor neuron degeneration is a hallmark of SMA pathology. Using ChAT as a motor neuron marker, we compared the number of $\alpha$-motor neurons in lumbar segments L1L2 of severe SMA mice treated with ASO10-27 SC with or without ICV decoy; there was no significant difference between these groups, and, in both cases, the motor neuron number was comparable with that of heterozygous mice (Fig. 6C,D).

Recent studies revealed NMJ defects as a characteristic feature of SMA pathology and potentially the cause of, or a contributor to, motor neuron death and muscle atrophy (Kariya et al. 2008). Muscles are selectively affected, and one of the most vulnerable muscles in the SMN $\Delta 7$ mouse model is the longissimus capitus, which shows $\sim 28 \%$ fully denervated fibers in this slightly milder model at the end stage (P12-P14) (Ling et al. 2012). We first examined the NMJ architecture in this muscle using in toto staining of teased muscle fibers from the severe mouse model. Motor endplates, presynaptic terminals, and neurofilaments were labeled with $\alpha$-bungarotoxin and antibodies against synaptophysin and neurofilament- $M$ isoform, respectively. Postsynaptic acetylcholine receptor (AChR) clusters have been classified into five sequential stages based on their topological complexity during postnatal development: plaque-shaped, ring-shaped/perforated, fold/ C-shaped, branched, and pretzel-like (Kummer et al. 2004; Sahashi et al. 2012). We did not observe fully denervated fibers in the longissimus capitus in this mouse model (Fig. 6E), but immature plaque-shaped AChR aggregates were prevalent in P9 SMA mice compared with heterozygous controls that had more mature (branched or pretzellike AChR) aggregates, indicating a defect in endplate maturation (Fig. 6F). We next compared the NMJ AChR topology of the longissimus capitus between the SC-alone and SC+decoy groups. Muscle samples were collected on P21; we observed no significant differences between the two treatment groups, and both were similar to the heterozygous controls (Fig. 6G).

Finally, despite the lack of anatomical and behavioral differences between rescued mice in the SC-alone and coadministered groups, we attempted to detect subtle differences in motor function using grip strength and rotarod tests. There was no difference in forelimb grip

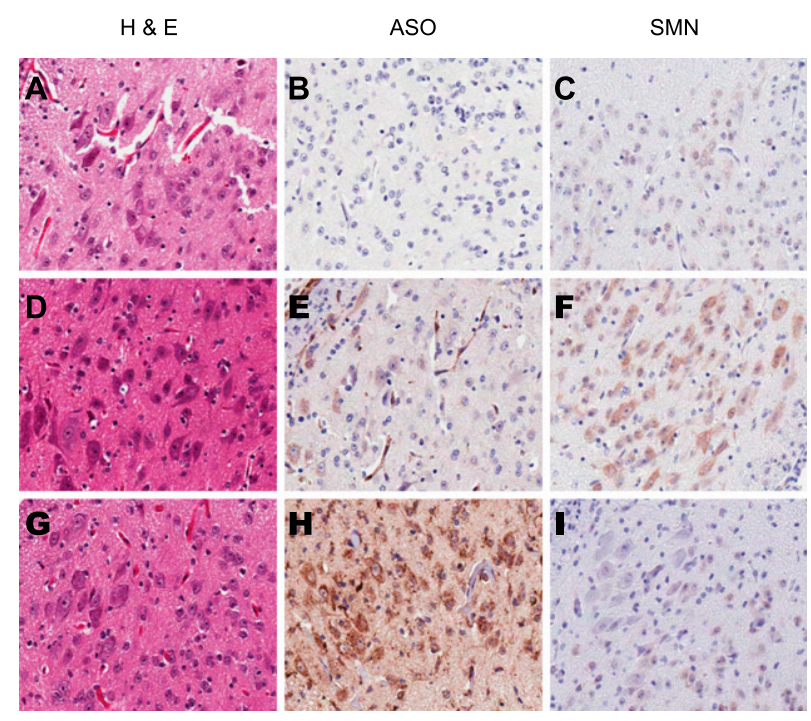

Figure 4. Immunohistochemical staining of ASO and SMN in spinal cord cross-sections of severe SMA mice. Mice were treated with either SC and ICV injections of saline $(A-C$; untreated), three SC injections (one injection per day between $\mathrm{P} 0$ and $\mathrm{P} 2$ ) of ASO10-27 alone at $120 \mathrm{mg} / \mathrm{kg}$ (D-F; SC-alone), or both SC injections of ASO10-27 as in the SC-alone group and ICV injection of $30 \mu \mathrm{g}$ of decoy oligonucleotide, on P0 $(10 \mu \mathrm{g})$ and P2 $(20 \mu \mathrm{g})(G-I ; \mathrm{SC}+$ decoy). Tissues were collected on P7 ( $n=3$ for all groups). $A, D$, and $G$ were stained with hematoxylin and eosin (H\&E). $B, E$, and $H$ were probed with a rabbit polyclonal antibody that recognizes the phosphorothioate backbone of both ASO10-27 and the decoy oligonucleotide. C, F, and $I$ were probed with a monoclonal human-specific anti-SMN antibody, SMN-KH. Nuclei were counterstained with DAPI. 

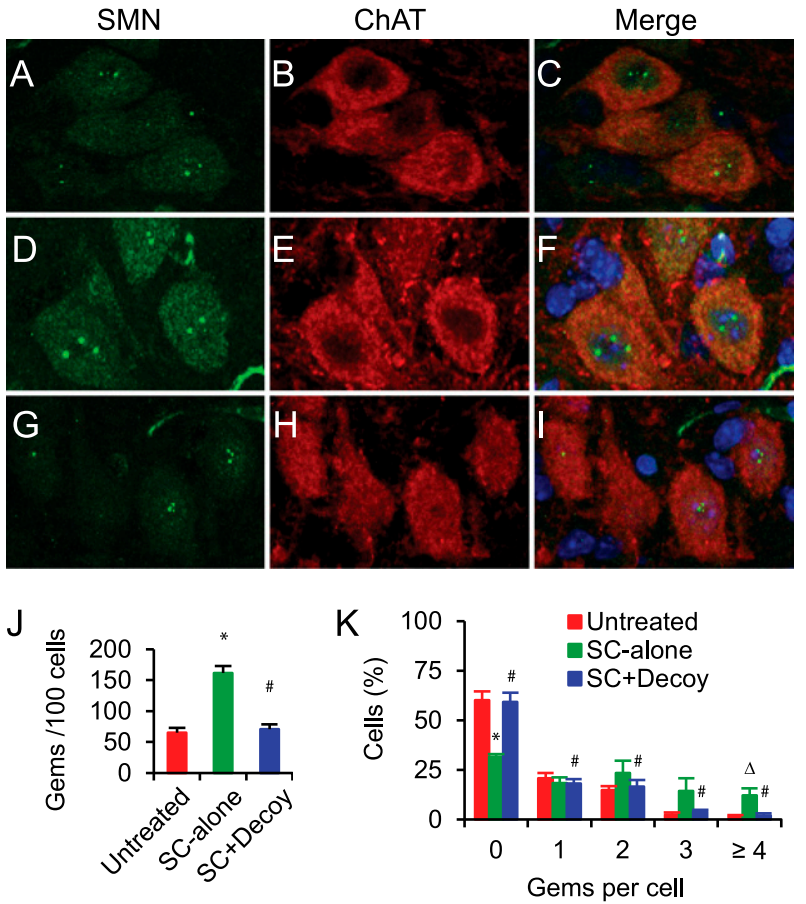

Figure 5. Gem counts in spinal cord L1-L2 motor neurons of mice. Mice were treated with either SC and ICV injections of saline $(A-C$; untreated, $n=3)$, three $S C$ injections (one injection per day between P0 and P2) of ASO10-27 alone at $120 \mathrm{mg} / \mathrm{kg}$ $(D-F$; SC-alone, $n=3)$, or both SC injections of ASO10-27 as in the SC-alone group and ICV injection of $30 \mu \mathrm{g}$ of decoy oligonucleotide on P0 $(10 \mu \mathrm{g})$ and P2 $(20 \mu \mathrm{g})(G-I$; SC+decoy, $n=3)$. Tissues were collected on P7. Immunofluorescence of paraffin-embedded sections was carried out to detect SMN and ChAT; nuclei were counterstained with DAPI. Gems per 100 motor neurons $(J)$ and percentage of motor neurons containing zero, one, two, three, or four or more gems $(K)$ in the above three groups were calculated. $\left(^{\star}\right) P<0.01$ versus the other two groups; $(\Delta) P<0.05$ versus the other two groups; (\#) $P>0.05$ versus untreated mice.

strength at $2-3$ mo (Fig. $6 \mathrm{H})$. The rotarod test likewise showed no significant difference in performance between the two groups (Fig. 6H).

\section{Discussion}

It has been generally accepted that spinal cord $\alpha$-motor neurons are the principal and directly affected cells in SMA and that motor neuron defects cause global muscle atrophy, leading to serious consequences, including respiratory failure and premature death in the more severe forms of SMA. Therefore, increasing SMN in motor neurons has been presumed to be essential and potentially sufficient for effective SMA therapy. Gavrilina et al. (2008) reported that a small increase of SMN in neurons strikingly extended the survival of severe SMA mice carrying an SMN cDNA transgene driven by a neuronspecific promoter. However, the mouse prion promoter used in that study is also active in many nonneuronal cell types and peripheral tissues (Brown et al. 1990), which may have contributed to phenotypic rescue. Indeed, several recent studies using various mouse models showed that restoring SMN expression only in motor neurons or pan-neuronally resulted in a limited survival increase (Gogliotti et al. 2012; Lee et al. 2012; Martinez et al. 2012). In accordance with these findings, we recently demonstrated an essential role of SMN expression in peripheral tissues for long-term rescue of severe SMA mice (Hua et al. 2011).

Although accumulating evidence has revealed the critical importance of cells other than motor neurons in SMA pathogenesis, it is still a consensus view that increasing SMN in the CNS, particularly spinal cord motor neurons, is at least required, if not sufficient, for SMA therapy. In the present study, we used ASO10-27 and a decoy neutralizer to address whether the CNS is an essential target for rescuing SMA mice. To our surprise, we found that restoring SMN expression in the CNS is not required for rescuing either mild or severe SMA mice. First, we showed that systemic administration of ASO1027 in mild SMA mice efficiently promoted tail growth and completely prevented the distal necrosis and that such rescue did not require increasing SMN in the CNS. Second, we showed that restoring SMN expression in peripheral tissues alone robustly rescued severe SMA mice, resulting in a 21-fold increase of life span as well as improved motor neuron counts and NMJ morphology. Our data demonstrate that peripheral tissues play a key role in SMA pathology, including tissue necrosis, motor neuron loss, motor defects, and premature death in mouse models.

The mild mouse models do not exactly phenocopy human type III SMA. The overt phenotype of these mouse models is distal tissue necrosis, particularly in the tail and ear pinnae, due to compromised vascular perfusion and subsequent thrombosis (Tsai et al. 2006; Narver et al. 2008), which has not been documented in patients with types II-IV SMA. However, vasculopathy has been occasionally observed in type I patients when their survival was significantly extended due to improvements in palliative care (Araujo et al. 2009; Rudnik-Schoneborn et al. 2010). Similarly, necrosis in the tail, ear pinnae, feet, legs, anus, etc. is manifested in severe SMA mice when their survival is extended after treatment with therapeutic drugs (Narver et al. 2008; Hua et al. 2011; Passini et al. 2011; Porensky et al. 2012).

According to our earlier study, the life span of ASOrescued mice negatively correlates with the severity of necrosis (Hua et al. 2011), suggesting that vascular necrosis may play a role in premature death. The mechanism leading to the vascular abnormality is unknown; our data suggest that the CNS components of the skeletal muscle motor units as well as the autonomic nervous system (ANS) are not involved in distal tissue necrosis.

The full rescue of necrosis in mild SMA mice achieved by peripheral SMN increase appears inconsistent with our previous study, in which we observed delay of necrosis by embryonic or neonatal ICV injection of ASO10-27 (Hua et al. 2010). However, in contrast to the CNS administration, the systemic ASO administration resulted in complete rescue. The fact that CNS administration resulted in a delay in tail and ear necrosis is likely due to partial ASO 
clearance from the CNS into the blood and subsequent uptake by peripheral tissues. Indeed, neonatal SC injection with only 10 or $20 \mu \mathrm{g}$ of ASO10-27 resulted in a rescue of necrosis similar to that observed with the ICV delivery route (Supplemental Fig. 3).

The most surprising discovery in the present study is that long-term survival (21-fold increase) as well as motor function improvements, rescue of motor neuron counts, and NMJ maturation in ASO-treated severe SMA mice did not require SMN levels to increase in the CNS. This unexpected finding indicates that the basal SMN protein levels in the CNS are already sufficient for normal mouse development, provided that a sufficient increase in SMN
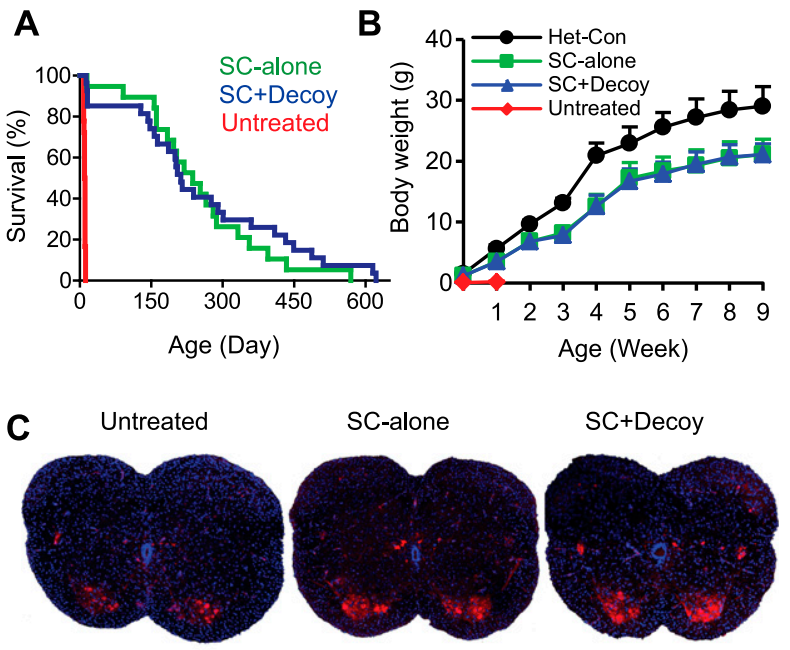

D

E
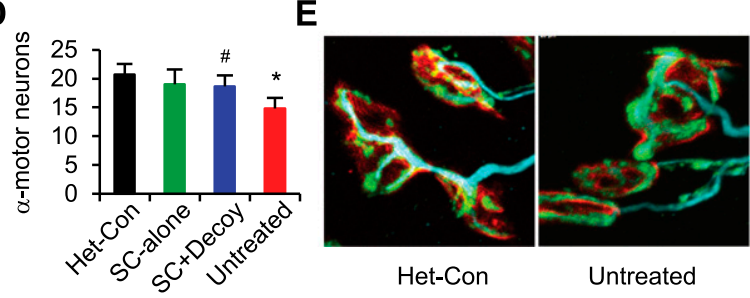

$\mathbf{F}$

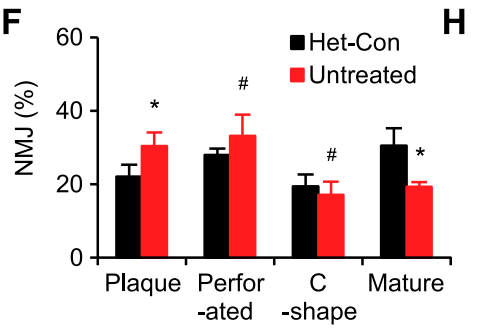

H

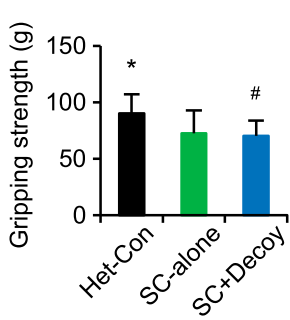

G

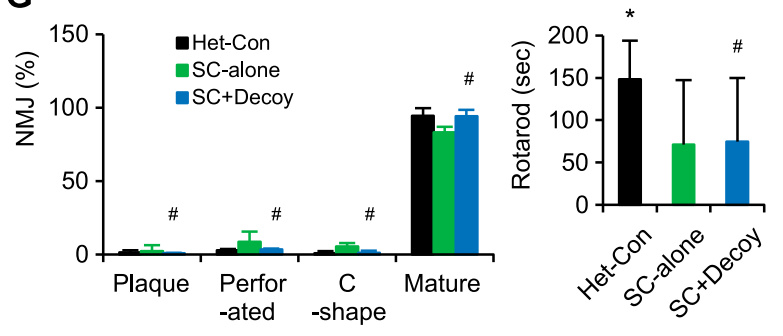

levels in peripheral tissues can be achieved. Consistent with this interpretation, using a conditional knockout strategy, Park et al. (2010) recently found that $70 \%$ of mice with selective depletion of SMN in motor neurons survived over a year.

Porensky et al. (2012) reported that ICV injection of PMO ASO10-29 at a dose of 27, 54, or $81 \mu \mathrm{g}$ in the SMN $\Delta 7$ model (which has a slightly milder phenotype than the severe model that we used here) led to a sixfold to sevenfold survival increase; the investigators proposed that early and sustained increase of SMN in the CNS is essential for SMA therapy. However, the strong survival increase that they reported was less striking than what we obtained in the more severe model with peripheral rescue alone. In addition, as stated above, some of the ASO injected into the CNS is cleared with CSF into the blood and circulates to peripheral tissues. Porensky et al. (2012) reported no statistically significant peripheral effect on SMN2 splicing after ICV injection of the middle dose; however, this may be attributable to the small sample size $(n=2)$, as an approximately twofold increase in SMN2 full-length mRNA in the liver and heart was actually observed. A more recent study using 25mer PMO (PMO25) confirmed that systemic delivery at high doses robustly rescues severe SMA mice (Zhou et al. 2013). Compared with our previous ICV rescue data, the PMO ASOs appeared to result in stronger rescue (at higher doses) through ICV delivery (Hua et al. 2011; Passini et al. 2011). However, the differences in animal models, ASO

Figure 6. Increase of SMN in peripheral tissues alone robustly rescued the phenotype of severe SMA mice. The SC-alone group was treated with three SC injections of ASO10-27 at $120 \mathrm{mg} / \mathrm{kg}$ at $\mathrm{P} 0-\mathrm{P} 2$, the $\mathrm{SC}+\mathrm{decoy}$ group was treated as in the SC-alone group plus ICV delivery of $30 \mu \mathrm{g}$ decoy at P0-P2, and mice that received SC and ICV injections of saline were used as controls (untreated). (A) Survival curves. $P<0.001$ for either the SC-alone $(n=19)$ or the SC+decoy $(n=27)$ group versus untreated mice $(n=18) . P=0.5496$ for the SC-alone versus the SC+decoy group. (B) Body weight curves were similar for the SC-alone and SC + decoy groups. Untreated heterozygous littermates (Het-Con, $n=12$ ) were used as positive controls. (C) Immunofluorescence of spinal cord L1-L2 sections with primary antibody against ChAT and Alexa fluor 568 secondary antibody. Nuclei were counterstained with DAPI. Tissues were collected on P7. (D) Motor neurons in the spinal cord L1-L2 ventral horn labeled as in $C$ were counted $(n=6) .\left(^{\star}\right) P<0.01$ versus all three groups; (\#) $P>0.05$ versus the SC-alone group. (E) NMJ staining of the longissimus capitus of SMA mice (untreated) and heterozygous littermates (Het-Con) reveals no denervation of this muscle. Tissues were collected on P9. Representative pictures are shown. (Red) Endplates; (blue) synaptic vesicles; (green) neurofilaments. $(F)$ Quantitation of AChR cluster shapes of the longissimus capitus $(n=3)$ NMJs $(n>100)$ as stained in E. Mature AChR clusters include branched and pretzel-like clusters. $\left(^{\star}\right) P<0.05$ versus heterozygous controls. $(G)$ Quantitation of AChR cluster shapes of the longissimus capitus NMJs $(n>100)$ in P21 mice $(n=3)$. (\#) $P>0.05$ compared with the other two groups. $(H)$ Grip strength and rotarod tests of rescued SMA mice $(n=10)$ at 2-3 mo of age. $\left({ }^{\star}\right) P<0.05$ versus the other two groups; $(\#) P>0.05$ versus the SC-alone group. 
lengths, treatment timing, and dosage between these separate studies likely influenced the therapeutic outcome. Thus, a more systematic study is needed to rigorously compare ASO chemistries through either ICV or systemic delivery routes.

Our data reveal that low basal levels of SMN in the CNS, together with increased SMN in peripheral tissues, are sufficient to maintain relatively normal NMJ architecture and motor neuron function, suggesting a non-cellautonomous mechanism of motor neuron degeneration in SMA. On the other hand, in several studies, including our own, selective depletion of SMN in motor neurons induces NMJ defects, and restoration of SMN rescues them, indicating a cell-autonomous mechanism (Park et al. 2010; Gogliotti et al. 2012; Lee et al. 2012; Martinez et al. 2012; Sahashi et al. 2012, 2013). This apparent discrepancy may be due to the extremely low SMN levels in motor neurons in these studies. Here we provide direct evidence demonstrating that cells outside the CNS contribute to the maintenance of motor neurons.

Noncell autonomy is a well-established phenomenon in several neurodegenerative diseases. For example, microglia and astrocytes significantly contribute to motor neuron death in mutant $\mathrm{Cu} / \mathrm{Zn}$ superoxide dismutase (SOD1)-induced amyotrophic lateral sclerosis (Ilieva et al. 2009). In the case of SMA, supporting cells, such as Schwann cells, may be an important contributing factor in NMJ pathology. Indeed, a recent study revealed a reduction of terminal Schwann cells in the $\mathrm{Smn}^{2 B /-}$ mouse model (Murray et al. 2012). Alternatively, or in addition, healthy peripheral tissues may supply essential neurotrophic factors or prevent the production of toxic factors that affect motor neuron maintenance. The systemic milieu affecting neural activities has been well documented; for example, an increase in circulating chemokines partly contributes to the aging-related decline of neurogenesis and impaired learning and memory (Villeda et al. 2011). We and others have shown that circulating IGF1, a neurotrophic factor produced in the liver, is reduced in SMA mice and restored upon systemic ASO therapy (Hua et al. 2011; Murdocca et al. 2012).

Selective restoration of SMN expression in neurons or muscles does not efficiently improve the survival of severe SMA mice (Gogliotti et al. 2012; Lee et al. 2012; Martinez et al. 2012). Here, we further showed that increasing SMN in the CNS is not required for efficient rescue of severe SMA mice. It remains to be seen to what extent the present observations, made in neonate mouse models, are directly relevant to human SMA. We note that various SMA therapeutic strategies-some already in clinical trials-were tested and optimized in similar mouse models, so developing a detailed understanding of the similarities and differences in SMA pathophysiology in human versus mouse models will be crucial.

\section{Materials and methods}

\section{Oligonucleotide synthesis}

The synthesis and purification of ASO10-27 (5'-TCACTTTCA TAATGCTGG-3') and decoy (5'-CCAGCATTATGAAAGTGA-3')
MOE-modified oligonucleotides with phosphorothioate backbone and all 5-methylcytosines were performed as described (Hua et al. 2010). The oligonucleotides were dissolved in $0.9 \%$ saline.

\section{Animals and oligonucleotide treatment}

All mouse protocols were in accordance with Cold Spring Harbor Laboratory's Institutional Animal Care and Use Committee guidelines. The mild Hung mouse model $\left(\mathrm{Smn}^{-/-} ; \mathrm{SMN}^{2 \mathrm{TG} / 2 \mathrm{TG}}\right)$ was the strain FVB.Cg-Tg(SMN2)2HungSMN1 $1^{\text {tm1Hung }} / \mathrm{J}$, founder line 2, purchased from Jackson Laboratory (stock no. 005058). The severe SMA model $\left(\mathrm{Smn}^{-/-}\right.$; $\left.S M N 2^{2 \mathrm{TG} / 0}\right)$ was generated as previously described (Hua et al. 2011). The oligonucleotide solutions were injected subcutaneously into the upper back or intracerebroventricularly with a $5-\mu \mathrm{L}$ syringe and 33-gauge custom removable needle (Hamilton) as described (Hua et al. 2010).

\section{Radioactive RT-PCR and Western blotting}

Fresh mouse tissues were rinsed with $0.9 \%$ saline and snapfrozen in liquid $\mathrm{N}_{2}$. Collection of total RNA and protein samples, RT-PCR with ${ }^{32} \mathrm{P}$-dCTP, PCR product analysis, Western blotting, and protein quantitation were as described previously (Hua et al. 2011). The monoclonal antibody against SMN, polyclonal antibody against $\beta$-tubulin, and secondary antibody IRDye $800 \mathrm{CW}$ - or $700 \mathrm{CW}$-conjugated goat anti-mouse or anti-rabbit were purchased from BD Biosciences, GenScript, and LI-COR.

\section{Histology}

Spinal cords were fixed with $4 \%(\mathrm{v} / \mathrm{v})$ formaldehyde in phosphate-buffered saline overnight. Oligonucleotide and SMN immunohistochemistry was performed as described (Hua et al. 2010). For gem counting in motor neurons and motor neuron counting in lumbar spinal cord segments L1-L2, paraffin-embedded $6-\mu \mathrm{m}$ sections were treated with citrate buffer for antigen retrieval (Sahashi et al. 2012) and incubated with goat anti-ChAT antibody (Millipore) and/or mouse SMN antibody (BD Bioscience) followed by donkey anti-goat Alexa fluor 568 (Invitrogen) and/or donkey anti-mouse Alexa fluor 488 secondary antibodies. For NMJ staining, after perfusing and post-fixing, the longissimus capitus was dissected and teased into layers five to 10 fibers thick; NMJ was stained as previously described (Sahashi et al. 2012). Confocal immunofluorescence imaging was performed with an LSM710 confocal microscope (Carl Zeiss) by merging Z-stacks of multiple planes into one image.

\section{Motor function tests}

Grip strength was measured using a grip strength meter (Columbus Instruments) as previously described (Hua et al. 2011). Rotarod tests were carried out with a RotaRodIV instrument (AccuScan); the rotation was set at a constant rate of $5 \mathrm{rpm}$ in one direction for a maximum of $180 \mathrm{sec}$. Among 10 trials for each mouse, the longest time that the mouse stayed on the rod was recorded.

\section{Statistical analysis}

Statistical significance was analyzed by two-tailed Student's $t$-tests. Kaplan-Meier survival curves were prepared with Prism 5 (GraphPad) and analyzed with the Mantel-Cox test. $P<0.05$ was considered statistically significant; in all of the figures, data are presented as mean $+\mathrm{SD}$. 


\section{Acknowledgments}

We gratefully acknowledge the support from National Institutes of Health grant R37 GM42699, the St. Giles Foundation, and Cold Spring Harbor Laboratory (CSHL). We also thank K.K.Y. Ling for advice on NMJ architecture analysis, and S. Hearn for assistance with microscope imaging. This work was performed with assistance from CSHL Shared Resources, which are funded in part by Cancer Center Support Grant 5P30CA045508. This work was also supported in part by the National Natural Science Foundation of China (81271423 and 81471298).

\section{References}

Araujo A, Araujo M, Swoboda KJ. 2009. Vascular perfusion abnormalities in infants with spinal muscular atrophy. I Pediatr 155: 292-294.

Bevan AK, Hutchinson KR, Foust KD, Braun L, McGovern VL, Schmelzer L, Ward JG, Petruska JC, Lucchesi PA, Burghes $\mathrm{AH}$, et al. 2010. Early heart failure in the SMN $\Delta 7$ model of spinal muscular atrophy and correction by postnatal scAAV9-SMN delivery. Hum Mol Genet 19: 3895-3905.

Bowerman M, Swoboda KJ, Michalski JP, Wang GS, Reeks C, Beauvais A, Murphy K, Woulfe I, Screaton RA, Scott FW, et al. 2012. Glucose metabolism and pancreatic defects in spinal muscular atrophy. Ann Neurol 72: 256-268.

Braun S, Croizat B, Lagrange MC, Warter JM, Poindron P. 1995. Constitutive muscular abnormalities in culture in spinal muscular atrophy. Lancet 345: 694-695.

Brown HR, Goller NL, Rudelli RD, Merz GS, Wolfe GC, Wisniewski HM, Robakis NK. 1990. The mRNA encoding the scrapie agent protein is present in a variety of nonneuronal cells. Acta Neuropathol 80: 1-6.

Cifuentes-Diaz C, Nicole S, Velasco ME, Borra-Cebrian $C_{,}$ Panozzo C, Frugier T, Millet G, Roblot N, Joshi V, Melki J. 2002. Neurofilament accumulation at the motor endplate and lack of axonal sprouting in a spinal muscular atrophy mouse model. Hum Mol Genet 11: 1439-1447.

Crawford TO, Pardo CA. 1996. The neurobiology of childhood spinal muscular atrophy. Neurobiol Dis 3: 97-110.

Gavrilina TO, McGovern VL, Workman E, Crawford TO, Gogliotti RG, DiDonato CJ, Monani UR, Morris GE, Burghes AH. 2008. Neuronal SMN expression corrects spinal muscular atrophy in severe SMA mice while muscle-specific SMN expression has no phenotypic effect. Hum Mol Genet 17: 1063-1075.

Gogliotti RG, Quinlan KA, Barlow CB, Heier CR, Heckman CJ, DiDonato CJ. 2012. Motor neuron rescue in spinal muscular atrophy mice demonstrates that sensory-motor defects are a consequence, not a cause, of motor neuron dysfunction. I Neurosci 32: 3818-3829.

Hamilton G, Gillingwater TH. 2013. Spinal muscular atrophy: going beyond the motor neuron. Trends Mol Med 19: 40-50.

Hayhurst M, Wagner AK, Cerletti M, Wagers AJ, Rubin LL. 2012. A cell-autonomous defect in skeletal muscle satellite cells expressing low levels of survival of motor neuron protein. Dev Biol 368: 323-334.

Heier CR, Satta R, Lutz C, DiDonato CJ. 2010. Arrhythmia and cardiac defects are a feature of spinal muscular atrophy model mice. Hum Mol Genet 19: 3906-3918.

Hsieh-Li HM, Chang JG, Jong YJ, Wu MH, Wang NM, Tsai CH, Li H. 2000. A mouse model for spinal muscular atrophy. Nat Genet 24: 66-70.

Hua Y, Vickers TA, Baker BF, Bennett CF, Krainer AR. 2007. Enhancement of SMN2 exon 7 inclusion by antisense oligonucleotides targeting the exon. PLOS Biol 5: e73.
Hua Y, Vickers TA, Okunola HL, Bennett CF, Krainer AR. 2008. Antisense masking of an hnRNP A1/A2 intronic splicing silencer corrects SMN2 splicing in transgenic mice. Am I Hum Genet 82: 834-848.

Hua Y, Sahashi K, Hung G, Rigo F, Passini MA, Bennett CF, Krainer AR. 2010. Antisense correction of SMN2 splicing in the CNS rescues necrosis in a type III SMA mouse model. Genes Dev 24: 1634-1644.

Hua Y, Sahashi K, Rigo F, Hung G, Horev G, Bennett CF, Krainer AR. 2011. Peripheral SMN restoration is essential for longterm rescue of a severe spinal muscular atrophy mouse model. Nature 478: 123-126.

Ilieva H, Polymenidou M, Cleveland DW. 2009. Non-cell autonomous toxicity in neurodegenerative disorders: ALS and beyond. J Cell Biol 187: 761-772.

Jablonka S, Beck M, Lechner BD, Mayer C, Sendtner M. 2007. Defective $\mathrm{Ca}^{2+}$ channel clustering in axon terminals disturbs excitability in motoneurons in spinal muscular atrophy. J Cell Biol 179: 139-149.

Kariya S, Park GH, Maeno-Hikichi Y, Leykekhman O, Lutz C, Arkovitz MS, Landmesser LT, Monani UR. 2008. Reduced SMN protein impairs maturation of the neuromuscular junctions in mouse models of spinal muscular atrophy. Hum Mol Genet 17: 2552-2569.

Kong L, Wang X, Choe DW, Polley M, Burnett BG, BoschMarce M, Griffin JW, Rich MM, Sumner CJ. 2009. Impaired synaptic vesicle release and immaturity of neuromuscular junctions in spinal muscular atrophy mice. J Neurosci 29: 842-851.

Kummer TT, Misgeld T, Lichtman JW, Sanes JR. 2004. Nerveindependent formation of a topologically complex postsynaptic apparatus. J Cell Biol 164: 1077-1087.

Le TT, Pham LT, Butchbach ME, Zhang HL, Monani UR, Coovert DD, Gavrilina TO, Xing L, Bassell GJ, Burghes AH. 2005. SMN $\Delta 7$, the major product of the centromeric survival motor neuron (SMN2) gene, extends survival in mice with spinal muscular atrophy and associates with fulllength SMN. Hum Mol Genet 14: 845-857.

Lee YI, Mikesh M, Smith I, Rimer M, Thompson W. 2011. Muscles in a mouse model of spinal muscular atrophy show profound defects in neuromuscular development even in the absence of failure in neuromuscular transmission or loss of motor neurons. Dev Biol 356: 432-444.

Lee AJ, Awano T, Park GH, Monani UR. 2012. Limited phenotypic effects of selectively augmenting the SMN protein in the neurons of a mouse model of severe spinal muscular atrophy. PLOS ONE 7: e46353.

Lefebvre S, Burglen L, Reboullet S, Clermont O, Burlet P, Viollet L, Benichou B, Cruaud C, Millasseau P, Zeviani M, et al. 1995. Identification and characterization of a spinal muscular atrophy-determining gene. Cell 80: 155-165.

Ling KK, Lin MY, Zingg B, Feng Z, Ko CP. 2010. Synaptic defects in the spinal and neuromuscular circuitry in a mouse model of spinal muscular atrophy. PLOS ONE 5: e15457.

Ling KK, Gibbs RM, Feng Z, Ko CP. 2012. Severe neuromuscular denervation of clinically relevant muscles in a mouse model of spinal muscular atrophy. Hum Mol Genet 21: 185-195.

Liu H, Beauvais A, Baker AN, Tsilfidis C, Kothary R. 2011. Smn deficiency causes neuritogenesis and neurogenesis defects in the retinal neurons of a mouse model of spinal muscular atrophy. Dev Neurobiol 71: 153-169.

Lorson CL, Hahnen E, Androphy EJ, Wirth B. 1999. A single nucleotide in the SMN gene regulates splicing and is responsible for spinal muscular atrophy. Proc Natl Acad Sci 96: 6307-6311. 
Martinez TL, Kong L, Wang X, Osborne MA, Crowder ME, Van Meerbeke JP, Xu X, Davis C, Wooley J, Goldhamer DJ et al. 2012. Survival motor neuron protein in motor neurons determines synaptic integrity in spinal muscular atrophy. I Neurosci 32: 8703-8715.

McAndrew PE, Parsons DW, Simard LR, Rochette C, Ray PN, Mendell JR, Prior TW, Burghes AH. 1997. Identification of proximal spinal muscular atrophy carriers and patients by analysis of SMNT and SMNC gene copy number. Am I Hum Genet 60: 1411-1422.

Meister G, Buhler D, Pillai R, Lottspeich F, Fischer U. 2001. A multiprotein complex mediates the ATP-dependent assembly of spliceosomal U snRNPs. Nat Cell Biol 3: 945-949.

Mentis GZ, Blivis D, Liu W, Drobac E, Crowder ME, Kong L, Alvarez FJ, Sumner CJ, O'Donovan MJ. 2011. Early functional impairment of sensory-motor connectivity in a mouse model of spinal muscular atrophy. Neuron 69: 453-467.

Monani UR, Lorson CL, Parsons DW, Prior TW, Androphy EJ, Burghes AH, McPherson JD. 1999. A single nucleotide difference that alters splicing patterns distinguishes the SMA gene SMN1 from the copy gene SMN2. Hum Mol Genet 8: 1177-1183.

Murdocca M, Malgieri A, Luchetti A, Saieva L, Dobrowolny G, de Leonibus E, Filareto A, Quitadamo MC, Novelli G, Musaro A, et al. 2012. IPLEX administration improves motor neuron survival and ameliorates motor functions in a severe mouse model of spinal muscular atrophy. Mol Med 18: 10761085.

Murray LM, Comley LH, Thomson D, Parkinson N, Talbot K, Gillingwater TH. 2008. Selective vulnerability of motor neurons and dissociation of pre- and post-synaptic pathology at the neuromuscular junction in mouse models of spinal muscular atrophy. Hum Mol Genet 17: 949-962.

Murray LM, Beauvais A, Bhanot K, Kothary R. 2012. Defects in neuromuscular junction remodelling in the $\mathrm{Smn}^{2 \mathrm{~B} /-}$ mouse model of spinal muscular atrophy. Neurobiol Dis 49C: $57-$ 67.

Narver HL, Kong L, Burnett BG, Choe DW, Bosch-Marce M, Taye AA, Eckhaus MA, Sumner CJ. 2008. Sustained improvement of spinal muscular atrophy mice treated with trichostatin A plus nutrition. Ann Neurol 64: 465-470.

Park GH, Maeno-Hikichi Y, Awano T, Landmesser LT, Monani UR. 2010. Reduced survival of motor neuron (SMN) protein in motor neuronal progenitors functions cell autonomously to cause spinal muscular atrophy in model mice expressing the human centromeric (SMN2) gene. J Neurosci 30: 12005-12019.

Passini MA, Bu J, Richards AM, Kinnecom C, Sardi SP, Stanek LM, Hua Y, Rigo F, Matson J, Hung G, et al. 2011. Antisense oligonucleotides delivered to the mouse CNS ameliorate symptoms of severe spinal muscular atrophy. Sci Transl Med 3: 72ra18.

Porensky PN, Mitrpant C, McGovern VL, Bevan AK, Foust KD, Kaspar BK, Wilton SD, Burghes AH. 2012. A single administration of morpholino antisense oligomer rescues spinal muscular atrophy in mouse. Hum Mol Genet 21: 1625-1638.

Riessland M, Ackermann B, Forster A, Jakubik M, Hauke J, Garbes L, Fritzsche I, Mende Y, Blumcke I, Hahnen E, et al. 2010. SAHA ameliorates the SMA phenotype in two mouse models for spinal muscular atrophy. Hum Mol Genet 19: 1492-1506.

Rigo F, Chun SI, Norris DA, Hung G, Lee S, Matson J, Fey RA, Gaus H, Hua Y, Grundy JS, et al. 2014. Pharmacology of a central nervous system delivered 2'-O-methoxyethyl-modified survival of motor neuron splicing oligonucleotide in mice and nonhuman primates. I Pharmacol Exp Ther 350: 46-55.
Rossoll W, Jablonka S, Andreassi C, Kroning AK, Karle K, Monani UR, Sendtner M. 2003. Smn, the spinal muscular atrophy-determining gene product, modulates axon growth and localization of $\beta$-actin mRNA in growth cones of motoneurons. J Cell Biol 163: 801-812.

Rudnik-Schoneborn S, Goebel HH, Schlote W, Molaian S, Omran H, Ketelsen U, Korinthenberg R, Wenzel D, Lauffer H, Kreiss-Nachtsheim M, et al. 2003. Classical infantile spinal muscular atrophy with SMN deficiency causes sensory neuronopathy. Neurology 60: 983-987.

Rudnik-Schoneborn S, Heller R, Berg C, Betzler C, Grimm T, Eggermann T, Eggermann K, Wirth R, Wirth B, Zerres K. 2008. Congenital heart disease is a feature of severe infantile spinal muscular atrophy. J Med Genet 45: 635-638.

Rudnik-Schoneborn S, Vogelgesang S, Armbrust S, GraulNeumann L, Fusch C, Zerres K. 2010. Digital necroses and vascular thrombosis in severe spinal muscular atrophy. Muscle Nerve 42: 144-147.

Ruiz R, Casanas JJ, Torres-Benito L, Cano R, Tabares L. 2010. Altered intracellular $\mathrm{Ca}^{2+}$ homeostasis in nerve terminals of severe spinal muscular atrophy mice. J Neurosci 30: 849-857.

Sahashi K, Hua Y, Ling KK, Hung G, Rigo F, Horev G, Katsuno M, Sobue G, Ko CP, Bennett CF, et al. 2012. TSUNAMI: an antisense method to phenocopy splicing-associated diseases in animals. Genes Dev 26: 1874-1884.

Sahashi K, Ling KK, Hua Y, Wilkinson JE, Nomakuchi T, Rigo F, Hung G, Xu D, Jiang YP, Lin RZ, et al. 2013. Pathological impact of SMN2 mis-splicing in adult SMA mice. EMBO Mol Med 5: 1586-1601.

Shababi M, Habibi J, Yang HT, Vale SM, Sewell WA, Lorson CL. 2010. Cardiac defects contribute to the pathology of spinal muscular atrophy models. Hum Mol Genet 19: 4059-4071.

Shanmugarajan S, Swoboda KJ, Iannaccone ST, Ries WL, Maria BL, Reddy SV. 2007. Congenital bone fractures in spinal muscular atrophy: functional role for SMN protein in bone remodeling. J Child Neurol 22: 967-973.

Shanmugarajan S, Tsuruga E, Swoboda KJ, Maria BL, Ries WL, Reddy SV. 2009. Bone loss in survival motor neuron (Smn ${ }^{-l-}$ SMN2) genetic mouse model of spinal muscular atrophy. I Pathol 219: 52-60.

Singh NK, Singh NN, Androphy EJ, Singh RN. 2006. Splicing of a critical exon of human survival motor neuron is regulated by a unique silencer element located in the last intron. Mol Cell Biol 26: 1333-1346.

Tsai LK, Tsai MS, Lin TB, Hwu WL, Li H. 2006. Establishing a standardized therapeutic testing protocol for spinal muscular atrophy. Neurobiol Dis 24: 286-295.

Villeda SA, Luo J, Mosher KI, Zou B, Britschgi M, Bieri G, Stan TM, Fainberg N, Ding Z, Eggel A, et al. 2011. The ageing systemic milieu negatively regulates neurogenesis and cognitive function. Nature 477: 90-94.

Wishart TM, Huang JP, Murray LM, Lamont DJ, Mutsaers CA, Ross J, Geldsetzer P, Ansorge O, Talbot K, Parson SH, et al. 2010. SMN deficiency disrupts brain development in a mouse model of severe spinal muscular atrophy. Hum Mol Genet 19: 4216-4228.

Yonekawa T, Komaki H, Saito Y, Sugai K, Sasaki M. 2013. Peripheral nerve abnormalities in pediatric patients with spinal muscular atrophy. Brain Dev 35: 165-171.

Zhou H, Janghra N, Mitrpant C, Dickinson RL, Anthony K, Price L, Eperon IC, Wilton SD, Morgan J, Muntoni F. 2013. A novel morpholino oligomer targeting ISS-N1 improves rescue of severe spinal muscular atrophy transgenic mice. Hum Gene Ther 24: 331-342. 


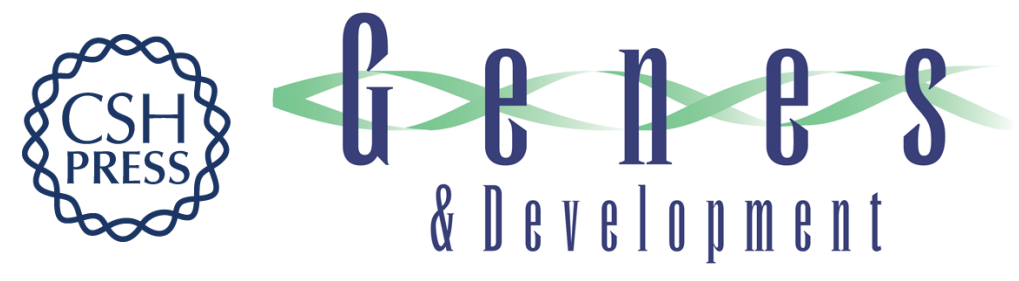

\section{Motor neuron cell-nonautonomous rescue of spinal muscular atrophy phenotypes in mild and severe transgenic mouse models}

Yimin Hua, Ying Hsiu Liu, Kentaro Sahashi, et al.

Genes Dev. 2015, 29: originally published online January 12, 2015

Access the most recent version at doi:10.1101/gad.256644.114

\section{Supplemental http://genesdev.cshlp.org/content/suppl/2015/01/09/gad.256644.114.DC1 \\ Material}

References This article cites 60 articles, 17 of which can be accessed free at:

http://genesdev.cshlp.org/content/29/3/288.full.html\#ref-list-1

Creative This article is distributed exclusively by Cold Spring Harbor Laboratory Press for the first Commons six months after the full-issue publication date (see

License http://genesdev.cshlp.org/site/misc/terms.xhtml). After six months, it is available under a Creative Commons License (Attribution-NonCommercial 4.0 International), as described at http://creativecommons.org/licenses/by-nc/4.0/.

Email Alerting Receive free email alerts when new articles cite this article - sign up in the box at the top Service right corner of the article or click here.

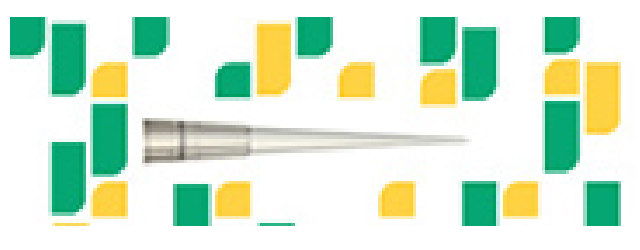

Focused on your science. 